\title{
Correlation between carbon-carbon bond length and the ease of retro Diels-Alder reaction
}

\author{
SAMBASIVARAO KOTHA*, SHAIBAL BANERJEE and MOBIN SHAIKH \\ Department of Chemistry, Indian Institute of Technology-Bombay, Powai, Mumbai, \\ Maharashtra, 400 076, India \\ e-mail: srk@chem.iitb.ac.in
}

MS received 28 April 2014; revised 22 August 2014; accepted 1 September 2014

\begin{abstract}
The bond length between C8-C9 in $\left(1^{\prime} R, 4^{\prime} S, 4 \mathrm{a}^{\prime} R, 8 \mathrm{a}^{\prime} S\right)-6^{\prime}, 7^{\prime}$-dimethyl-1', $4^{\prime}, 4 \mathrm{a}^{\prime}, 8 \mathrm{a}^{\prime}$-tetrahydrospiro [cyclopropane-1,9'-[1,4]methanonaphthalene]-5', $8^{\prime}$-dione is 1.571 (2) $\AA$ and between C7-C12 is 1.567 (2) $\AA$ which are longer than the corresponding bond length for saturated bicyclic systems (1.531-1.535 $\mathrm{A}$ ). This paper reports the correlation between bond length and the ease of retro Diels-Alder reaction.
\end{abstract}

Keywords. Crystal structures; retro Diels-Alder reaction; spirocyclic dienes.

\section{Introduction}

The Diels-Alder (DA) reaction is a versatile protocol for $\mathrm{C}-\mathrm{C}$ bond formation and also compatible with the wide range of functional groups. ${ }^{1}$ However, its reverse reaction i.e., retro Diels-Alder (rDA), has been relatively less explored owing to the high energy requirement to cross the activation barrier. ${ }^{2}$ Despite existing problems, rDA reaction has evolved as a useful tool and remains to be a preferred method for the preparation of several reactive olefins or metastable molecular entities. ${ }^{3,4}$ The rate of rDA reaction depends on several factors like the geometry of the adducts, hetero atoms, nature of substituents tagged with the adducts, catalysts used, etc. It is well known that trimethylsilyl group on a bicyclic DA adduct exerts a positive effect on the rate of rDA reaction. ${ }^{5}$ Similarly, Kotha and co-workers reported that cyclopropane ring containing norbornane also exerts a positive effect on the rDA reaction due to stabilization of the transition state. ${ }^{6}$ In addition to these factors, studies conducted by White and co-workers on the $\mathrm{rDA}$ reaction of bicyclic adducts have pointed out an interesting correlation between the bond distance of the carbon atoms involved in the bond breaking process and the rate of the $\mathrm{rDA}$ reaction. ${ }^{7,8}$ To this end, they have examined bond distance between the unsaturated norbornene and its saturated counterpart by x-ray crystallographic data (figure 1). It was observed that the bond length between $\mathrm{C} 1-\mathrm{C} 10$ and $\mathrm{C} 4-\mathrm{C} 5$ has been elongated in unsaturated system $\mathbf{1}$ as compared to the saturated

\footnotetext{
*For correspondence
}

system 2 . Therefore, the adduct $\mathbf{1}$ is more prone to $\mathrm{rDA}$ reaction. White and co-workers discussed the effect of orbital interactions on $\mathrm{rDA}$ reaction.

In the present manuscript, we examined the crystal structure of $\left(1^{\prime} \mathrm{R}, 4^{\prime} \mathrm{S}, 4 \mathrm{a}^{\prime} \mathrm{R}, 8 \mathrm{a}^{\prime} \mathrm{S}\right)-6^{\prime}, 7^{\prime}$-dimethyl$1^{\prime}, 4^{\prime}, 4 \mathrm{a}^{\prime}, 8 \mathrm{a}^{\prime}$-tetrahydrospiro[cyclopropane-1,9' -[1,4]methanonaphthalene]-5', $8^{\prime}$-dione and found that the bond length between atoms connecting diene and the dienophile is somewhat longer than the normal $\mathrm{C}-\mathrm{C}$ bond length. The increased bond length is responsible for the facile rDA reaction of $\mathbf{5}$.

\section{Experimental}

The detailed experimental method for the synthesis of $\mathbf{5}$ has previously been reported by us. ${ }^{6}$ The product 5 was recrystallized using hexane-ether solvent.

\section{Results and Discussion}

We have synthesized several cyclopropane containing spirocyclic dienes under mild reaction conditions. The spiro-diene $\mathbf{3}$ was reacted with 2,3-dimethylbenzoquinone $\mathbf{4}$ to deliver spirocyclic adduct $\mathbf{5}$ (scheme 1). The detailed experimental method has been reported in our earlier manuscript. ${ }^{6}$ The retro DielsAlder reaction for this bicyclic system $\mathbf{5}$ has been achieved by refluxing in toluene for $28 \mathrm{~h}$ with $35 \%$ yield.

After repeated attempts of crystallization from hexane-ether mixture, we were successful in getting the triclinic crystals of the DA adduct $\mathbf{5}$, whose structure 

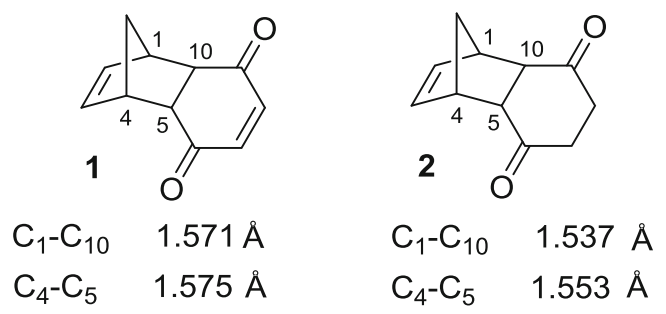

Figure 1. The molecular system examined by White and co-workers ${ }^{7,8}$ for correlation of bond distance with rDA reaction.

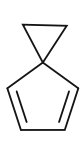

3<smiles>CC1=C(C)C(=O)C=[C+]C1=O</smiles>

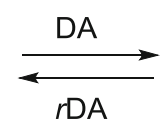

4

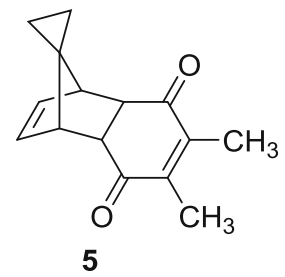

Scheme 1. The Diels-Alder and the retro Diels-Alder approaches to the norbornene system 5 .

was refined to an $\mathrm{R}$ factor of $4.24 \%$. The crystal data and the details of refinement are collected in table 1 . The adduct 5 has endo conformation with two methyl groups flanked away from the norbornane ring, cf. figure 2. It was observed for compound 5 that the distance for C8-C9 bond is 1.571 (2) $\AA$ and that for C7$\mathrm{C} 12$ bond is 1.567 (2) $\AA$ (figure 2). The bond distances observed for the carbon atoms of $\mathbf{5}$ involved in the bond breaking process are greater than the average $\mathrm{C}-\mathrm{C}$ bond distance generally found in a saturated bicyclic systems which is 1.531-1.535 $\mathrm{A}$. The cyclopropane bond, (C13-C14) is aligned in a near anti-periplanar conformation to the C8-C9 bond, which undergoes cleavage during the rDA reaction. The angles between C6-C7-C12 and C1-C8-C9 were found to be $112.81(13)^{\circ}$ and $113.03(13)^{\circ}$, respectively; clearly, the deviation from the normal angle of $109^{\circ}$ is significant. The greater bond lengths and strained conformation in the adduct $\mathbf{5}$ are possible reasons for the facile nature of the adduct to undergo rDA reaction.

We have also prepared a spirocyclic dione $\mathbf{6}$ and found no rDA reaction under the above mentioned conditions. It clearly indicates the role of cyclopropane ring in rDA reaction (scheme 2). ${ }^{9}$ Unfortunately, our unsuccessful efforts thus far in obtaining crystals of the adduct $\mathbf{6}$ for $\mathrm{x}$-ray structure determination preclude correlation, analogous to that of compound $\mathbf{5}$ of the bond lengths with reactivity.

Table 1. Crystal data and structure refinement details for compound $\mathbf{5}$.

\begin{tabular}{|c|c|}
\hline Empirical formula & $\mathrm{C}_{15} \mathrm{H}_{16} \mathrm{O}_{2}$ \\
\hline Formula weight & 228.28 \\
\hline Temperature & $150(2) \mathrm{K}$ \\
\hline Wavelength & $0.71073 \AA$ \\
\hline Crystal system, space group & Triclinic, $\mathrm{P}-1$ \\
\hline \multicolumn{2}{|l|}{ Unit cell dimensions } \\
\hline $\mathrm{a}=7.1512(9) \mathrm{A}$ & alpha $=64.04(3) \mathrm{deg}$. \\
\hline $\mathrm{b}=9.114(2) \mathrm{A}$ & beta $=88.829(16) \operatorname{deg}$ \\
\hline $\mathrm{c}=10.183(3) \mathrm{A}$ & gamma $=80.669(16) \mathrm{deg}$ \\
\hline$V / \AA^{3}$ & $587.9(2)$ \\
\hline Z, Calculated density & $2,1.290 \mathrm{Mg} / \mathrm{m} 3$ \\
\hline Absorption coefficient $\left(\mathrm{mm}^{-1}\right)$ & 0.084 \\
\hline $\mathrm{F}(000)$ & 244 \\
\hline Crystal size & $0.34 \times 0.26 \times 0.21 \mathrm{~mm}$ \\
\hline Theta range for data collection & 3.50 to $24.99 \mathrm{deg}$ \\
\hline Limiting indices & $-8<=\mathrm{h}<=8,-10<=\mathrm{k}<=10,-11<=\mathrm{l}<=12$ \\
\hline Reflections collected/unique & $4962 / 2058[\mathrm{R}($ int $)=0.0188]$ \\
\hline Completeness to theta $=24.99$ & $99.5 \%$ \\
\hline Absorption correction & Semi-empirical from equivalents \\
\hline Max. and min. transmission & 0.9825 and 0.9719 \\
\hline Refinement method & Full-matrix least-squares on $\mathrm{F}^{2}$ \\
\hline Data/restraints/parameters & $2058 / 0 / 156$ \\
\hline Goodness-of-fit on $\mathrm{F}^{2}$ & 1.091 \\
\hline Final $\mathrm{R}$ indices $[\mathrm{I}>2 \operatorname{sigma}(\mathrm{I})]$ & $\mathrm{R} 1=0.0424, \mathrm{wR} 2=0.1054$ \\
\hline $\mathrm{R}$ indices (all data) & $\mathrm{R} 1=0.0491, \mathrm{wR} 2=0.1098$ \\
\hline Largest diff. peak and hole & 0.273 and -0.225 e. $\mathrm{A}^{-3}$ \\
\hline
\end{tabular}




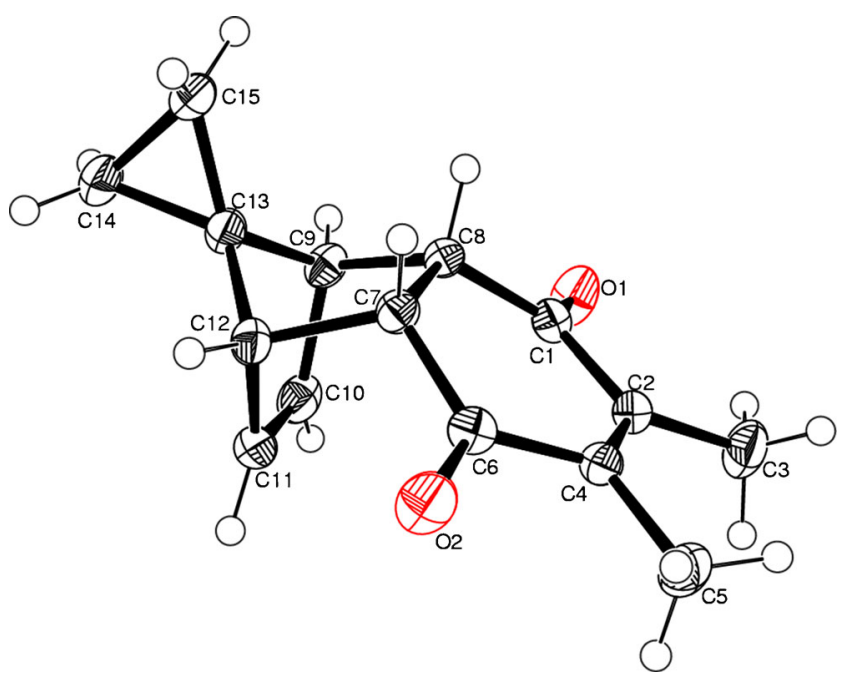

Figure 2. ORTEP perspective diagram of the structure of compound $\mathbf{5}$.

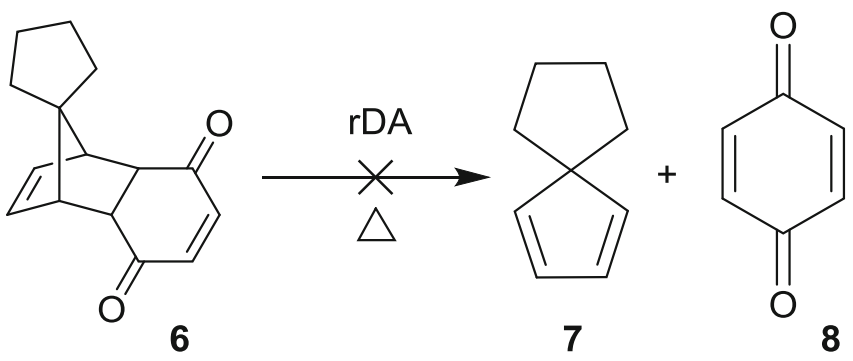

Scheme 2. Attempted retro Diels-Alder reaction of the norbornene system 6.

\section{Conclusion}

While the occurrence of Diels-Alder reactions are generally reconciled based on overlap of the frontier molecular orbitals, experimental results of retro Diels-Alder reactions have rarely been examined from the point of structural considerations. We have shown that the increase in the bond lengths of pertinent $\mathrm{C}-\mathrm{C}$ bonds, as revealed by $\mathrm{X}$-ray crystal structure analysis, is responsible for the observed facile retro Diels-Alder reaction of compound $\mathbf{5}$.

\section{Supplementary Information}

X-ray diffraction data were collected on an OXFORD XCALIBUR-S CCD single-crystal X-ray diffractometer. The structure was solved and refined by full-matrix least-squares techniques on F2 using the SHELX97 program (Sheldrick, 1997). Crystallographic data (excluding structure factors) for the structures reported in this paper have been deposited with the Cambridge Crystallographic Data Centre as supplementary publication Compound 5 CCDC 958630. Copies of available material can be obtained, free of charge, on application to the CCDC, 12 Union Road, Cambridge CB2 1EZ, UK (e-mail: deposit@ccdc.cam.ac.uk).

\section{Acknowledgements}

We would like to acknowledge the DST, New Delhi for the financial support. We also thank, SAIF-Mumbai for recording the spectral data. S K thanks DST, New Delhi for the award of a J C Bose fellowship. S K thanks Darshan Mhatre for his help regarding X-ray data collection.

\section{References}

1. Carruthers W 1990 In Cycloaddition Reactions in Organic Synthesis (Oxford: Pergamon press)

2. Seybold G 1977 Angew. Chem. Int. Ed. Engl. 89377

3. Kotha $\mathrm{S}$ and Banerjee S 2013 RSC Adv. 37642

4. Kashinath K, Swaroop P S and Reddy D S 2012 RSC Adv. 23596

5. Magnus P, Cairns P M and Moursounidis J $1987 \mathrm{~J}$. Am. Chem. Soc. 1092469

6. Kotha S, Banerjee S, Patil M P and Sunoj R B 2006 Org. Biomol. Chem. 41854

7. White J M, Birney D, Lim T K, Koh J H and Pool B R 2002 J. Am. Chem. Soc. 1245091

8. White J M and Pool B R 2000 Org. Lett. 23505

9. Kotha S, Manivannan E and Sreenivasachary N $1999 \mathrm{~J}$. Chem. Soc. Perkin Trans. 1192845 